\title{
Couple Relationship Education at Home: Does Skill Training Enhance Relationship Assessment and Feedback?
}

\author{
W. Kim Halford \\ University of Queensland \\ Keithia Wilson \\ Griffith University \\ Bronwyn Watson \\ Griffith University \\ Tony Verner \\ Jeffry Larson \\ Brigham Young University - Provo \\ Follow this and additional works at: https://scholarsarchive.byu.edu/facpub \\ Part of the Other Social and Behavioral Sciences Commons \\ See next page for additional authors

\section{Original Publication Citation} \\ Halford, W. K., Wilson, K., Watson, B., Verner, T., Larson, J.,Busby, D., \& Holman, T. (2010). Couple \\ relationship education at home: Does skill training enhance relationship assessment and \\ feedback? Journal of Family Psychology, 24, 188-196.
}

\section{BYU ScholarsArchive Citation}

Halford, W. Kim; Wilson, Keithia; Watson, Bronwyn; Verner, Tony; Larson, Jeffry; Busby, Dean M.; and Holman, Thomas, "Couple Relationship Education at Home: Does Skill Training Enhance Relationship Assessment and Feedback?" (2010). Faculty Publications. 4609.

https://scholarsarchive.byu.edu/facpub/4609

This Peer-Reviewed Article is brought to you for free and open access by BYU ScholarsArchive. It has been accepted for inclusion in Faculty Publications by an authorized administrator of BYU ScholarsArchive. For more information, please contact ellen_amatangelo@byu.edu. 


\section{Authors}

W. Kim Halford, Keithia Wilson, Bronwyn Watson, Tony Verner, Jeffry Larson, Dean M. Busby, and Thomas Holman

This peer-reviewed article is available at BYU ScholarsArchive: https://scholarsarchive.byu.edu/facpub/4609 


\title{
Couple Relationship Education at Home: Does Skill Training Enhance Relationship Assessment and Feedback?
}

\author{
W. Kim Halford \\ The University of Queensland \\ Tony Verner \\ Relationships Australia (Queensland)
}

\author{
Keithia Wilson and Bronwyn Watson \\ Griffith University
}

\author{
Jeffry Larson, Dean Busby, and Thomas Holman \\ Brigham Young University
}

\begin{abstract}
To evaluate the effective components of couple relationship education, 59 newlywed couples were randomly assigned to one of two couple relationship programs (CRE): (1) RELATE, which involved receiving feedback on their relationship based on the on-line RELATE assessment; or (2) RELATE + Couple CARE, which was RELATE plus completing the 6 unit Couple CARE relationship skill training program. Relative to RELATE, RELATE + Couple CARE produced more improvement in couple communication, and high relationship satisfaction across the next 12 months in women. Men sustained high and similar relationship satisfaction in either condition. Skill training CRE has additional benefits for couples beyond assessment and feedback.
\end{abstract}

Keywords: relationship satisfaction, relationship education, prevention, marriage education, couple

What are the important components of couple relationship education (CRE) that assist couples to sustain their relationship satisfaction? Previous research has identified two effective approaches to CRE: assessing couple relation-

W. Kim Halford, School of Psychology, The University of Queensland, St. Lucia, Australia; Keithia Wilson and Bronwyn Watson, School of Psychology, Griffith University, Brisbane, Australia; Tony Verner, Relationships Australia (Queensland), Queensland, Australia; Jeffry Larson, Dean Busby, and Thomas Holman, School of Family Life, Brigham Young University, Provo, Utah.

This research was supported by a Griffith University Research Industry Grant, with matching funds from Relationships Australia (Queensland) and the RELATE Institute of Brigham Young University. We thank Andrew Davis, Chief Executive Officer of Relationship Australia (Queensland) for his advocacy and support of the project; Raylene Chen, Beth Duncan, Kate Lloyd, Andrew Nicholson, and Sue Wilson of Relationships Australia (Queensland), and Claire Hitchings of Griffith University for their highly skilled work as relationship educators; and Liz Moore and Charles Farrugia of Griffith University for assisting with training and supervision of the relationship educators.

W. Kim Halford and Keithia Wilson are authors of Couple Care relationship education program. They receive royalties from the sale of the products that form the Couple CARE and associated programs. Dean Busby serves as the executive director of the RELATE Institute who pays his travel expenses for the annual meeting. Thomas Holman is on the board of the RELATE Institute who pays his travel expenses for the annual board meeting.

Correspondence concerning this article should be addressed to W. Kim Halford, School of Psychology, McElwain Building, The University of Queensland, St. Lucia QLD 4072, Australia. E-mail: k.halford@psy.uq.edu.au ships and providing feedback intended to guide self-change efforts, or curriculum-based education to teach important relationship knowledge and skills (Halford, Markman, \& Stanley, 2008). The current study evaluated the effects of adding curriculum-based skill training to relationship assessment and feedback.

\section{Relationship Assessment and Feedback as CRE}

There are two broad approaches to CRE that are often used by practitioners, and that have been evaluated in randomized controlled trials: (1) inventory-based relationship assessment and feedback; and (2) curriculum-based teaching of relationship knowledge, skills, and attitudes (Halford et al., 2008). Inventory-based assessments are used to give couples feedback about their relationship strengths and challenges based on the assumption that such feedback can guide couples to strengthen their relationships (Larson, Newell, Topham, \& Nichols, 2002). The most widely used inventories provide scores on dimensions like shared realistic expectations, effective communication and conflict resolution, and personal stress management. Scores on these questionnaires predict newlywed couples' future relationship satisfaction and stability (Larson et al., 2002), showing that they do assess relevant aspects of couple relationships.

There are three published studies evaluating the effects of assessment and feedback on couple relationships. In a quasiexperimental study, Knutson and Olson (2003) found that feedback based on the PREPARE inventory significantly improved premarital couples' relationship satisfaction relative to a no intervention comparison condition, though selfselection into conditions might explain the differential out- 
comes. A randomized controlled trial showed feedback using the Internet-based RELATE inventory increased relationship satisfaction relative to a wait list control (Larson, Vatter, Galbraith, Holman, \& Stahmann, 2007), though the maintenance of these effects was not evaluated. Busby, Ivey, Harris, and Ates (2007) found feedback based on the Internet-based RELATE inventory plus six sessions of skill training significantly enhanced relationship satisfaction relative to a guided reading control, and that this higher relationship satisfaction was sustained for at least six months. However, it is not possible to disentangle the effect of the assessment and feedback from the skill training provided. Whether the promising immediate effects of assessment and feedback found by Larson et al. (2007) are maintained long-term is as yet untested. However, it is known that some couples lack key relationship skills like effective communication (Bradbury \& Karney, 2004). Assessment with feedback might be insufficient to allow such couples to sustain relationship satisfaction, and they might benefit from relationship skill training.

\section{Curriculum-Based CRE}

Curriculum-based CRE is often referred to as the skilltraining approach because it focuses on training couples in key relationship skills (e.g., communication). Most of these programs also promote relationship knowledge (e.g., realistic, shared relationship expectations) (Carroll \& Doherty, 2003; Halford, Markman, Stanley, \& Kline, 2003) and positive connections and commitment (Markman, Stanley, Jenkins, Petrella, \& Wadsworth, 2006). Examples of evaluated CRE curricula include the Relationship Enhancement program (Guerney, 1987), the Prevention and Relationship Enhancement Program (PREP; Markman, Stanley, Blumberg, Jenkins, \& Whaley, 2004), and the Couple Commitment And Relationship Enhancement (Couple CARE) (Halford, Moore, Wilson, Dyer, \& Farrugia, 2004). Each of these CRE curricula involve 10 to 12 program hours that include modeling, rehearsal, and feedback of skills, as well as activities promoting beliefs and attitudes associated with healthy relationships (Halford et al., 2008).

Curriculum-based CRE produces immediate, large effect size enhancement of couple relationship skills, $d>0.7$, and moderate short-term (predominantly assessed within 3 months after CRE) enhancement of relationship satisfaction, $d=0.5$ (Hawkins, Blanchard, Baldwin, \& Fawcett, 2008). The established immediate benefits of CRE on relationship satisfaction are not evident in couples that initially have high satisfaction (Halford et al., 2008), which is likely attributable to a ceiling effect. CRE typically serves marrying couples when relationship satisfaction is usually high and there is little room to further improve satisfaction. However, across the first 10 years of marriage mean relationship satisfaction declines, and about $3 \%$ to $4 \%$ of couples separate each year (Glenn, 1998). The intent with CRE is to prevent this deterioration, and only long-term follow-up can really test whether relationship problems are prevented. Unfortunately, there are relatively few published studies assessing effects of CRE for more than 3 months in early stage relationships (Halford et al., 2008). Follow ups are needed that include sufficient time for deterioration in control couples to occur so that a prevention effect can be established in the CRE condition.

The existing curriculum-based CRE programs are offered with a standard curriculum, which fails to address the unique relationship challenges particular couples have in their relationship (Larson \& Halford, in press). All evaluated CRE curricula focus upon skills that research has identified as the most common challenges couples encounter in sustaining relationship satisfaction (Halford et al., 2008). However, even the most central of content common to all programs is not relevant to all couples. For example, reducing negative couple communication and preventing destructive conflict is a key ingredient in Relationship Enhancement, PREP, Couple CARE, and Couple Communication (Halford et al., 2003). This focus on reducing negative communication is based on research showing that negative communication in newlyweds predicts poor couple outcomes (Heyman, 2001). However, this prediction results from the heterogeneity of couples on initial couple communication. It follows that many marrying couples have low levels of negative communication, which predicts them being able to sustain high relationship satisfaction. Such couples seem unlikely to benefit from education that teaches communication emphasizing reduction of negative communication, as each of these CRE curricula do. Consistent with this interpretation, Halford, Sanders, and Behrens (2001) found only couples with initially high levels of negative communication showed long-term (after 4 years) benefits in sustaining high relationship satisfaction after CRE skill training focused on communication. Thus, for many couples it appears that communication skills training may not be necessary.

Because not all couples need all components of a program, participating in a fixed curriculum means many couples' participation might be wasting valuable time and money. Couples report that it is unhelpful to work through materials that are not directly applicable to their unique relationship needs (Busby et al., 2007), and learning concepts and skills irrelevant to their unique needs may demotivate the learner to participate in other more relevant curriculum components (Duncan \& Goddard, 2005). For example, individuals who have excellent communication skills but poor financial management skills may show low engagement with, or even drop out, of programs practicing communication skills. Moreover, no fixed curriculum can cover all of the potential risk factors relevant to couples. For example, stepfamily couples have unique challenges in their relationship that predict future relationship satisfaction, such as developing shared and realistic expectations of the step parent role (Nicholson, Phillips, Whitton, Halford, \& Sanders, 2007). These issues are not covered in existing evidence-based CRE curricula.

A challenge in offering customized CRE is that many current providers of CRE do not have the professional skills to carry out relationship assessments that might guide customizing (Doherty \& Anderson, 2004). However, relying on highly trained mental health professionals that can do such 
assessments to offer CRE is likely to severely limit the accessibility of CRE. There are not enough highly trained professionals to provide such services. One possible means to customize skill-based CRE is with the use of easily accessed, web-based assessments like RELATE, which is self-scoring and provides clear interpretative guidelines to educators and couples. This assessment and feedback can then be supplemented by curriculum-based CRE to provide required skill training.

\section{Rationale for Flexible Delivery}

CRE is delivered predominantly as face-to-face programs (Wilson \& Halford, 2008). A variety of professionals, religious leaders, and political opinion leaders advocate CRE attendance, but only a minority of marrying couples attends such programs (Halford, O'Donnell, Lizzio, \& Wilson, 2006). Many adults prefer to access psychological education through self-directed programs, which can be undertaken at times and places that suit participants, rather than through face-to-face programs (Taylor, Jobson, Winzelberg, \& Abascal, 2002). Across diverse applications of adult education, programs structured to allow ease of access and to promote self-directed learning are termed "flexible delivery" programs.

Information technology (IT) is being used as a means to flexibly deliver a wide range of psychological services. The technologies being used for these new services are diverse and include mobile (cell) telephones, Personal Digital Assistants (PDAs), video-and web-conferencing, Digital Video Discs (DVDs), and the Internet (Casey \& Halford, in press). Examples of applications of IT include assessment and treatment for a diverse range of problems including anxiety, depression (Spek et al., 2007), eating disorders (Taylor et al., 2002); and coping with major stresses like cancer and heart disease (Lieberman \& Goldstein, 2005); as well as preventive efforts to promote health enhancing behaviors (Kypri \& McAnally, 2005). Flexible delivery has the potential to enhance the reach of CRE as couples are more likely to read books (Doss, Rhoades, Stanley, \& Markman, 2009) or access a Web site (Casey \& Halford, in press) on relationships than attend face-to-face education.

RELATE is an online comprehensive assessment of a couple's relationship, which provides self-and partnerreports of current relationship strengths and challenges in domains like relationship satisfaction, communication, and conflict management (Busby, Holman, \& Taniguchi, 2001). These factors predict relationship satisfaction in newlywed couples (Holman, 2001). Relationship risk is operationalized as the number of relationship challenges a couple has, as assessed by RELATE, which predicts newlyweds' future relationship satisfaction and separation status (Holman, 2001). While some professionals might wonder about the validity of reports based on computer assessments, it has been long-established that people's reports of personal material to computer-based assessments is often more disclosing and reliable than that given to a professional interviewer (Garb, 2007).

Couple CARE (Halford et al., 2004) is a curriculum- based CRE program that couples can complete at home. The content is based upon the evaluated, skill-based face-to-face Self-PREP program (Halford et al., 2001). Couple CARE has four components: (a) a DVD that presents key ideas and models core relationship skills; (b) a guidebook that presents structured tasks that allow the couple to apply the key ideas to their relationship; (c) development of individual self-change plans by each partner; and (d) a series of telephone calls with a psychologist to review progress and assist with self-change plans. In the telephone calls the educator clarifies concepts, provides skill training, and coaches the partners in how to apply the ideas and skills within their relationship. A randomized controlled trial showed that couples engage with Couple CARE, and it produced immediate enhancement of couple relationship satisfaction (Halford et al., 2004). Furthermore, the extent to which couples acquired key relationship skills like effective communication and working at their relationship predicted maintenance of relationship satisfaction four years later (Halford \& Wilson, 2009).

\section{Research Aims and Hypotheses}

In summary, there is evidence that two approaches to CRE (assessment and feedback, and curriculum-based skill training) enhance couple relationship satisfaction, at least in the short-term. Assessment and feedback might be limited in its effects because it does not teach the relationship skills that at least some couples seem to lack. Existing skilltraining CRE might be limited in its effect because its fixed curriculum fails to tailor its content to a couple's particular relationship strengths and challenges. The aim of the current research was to evaluate the effects of adding the curriculum-based skill training in Couple CARE to the assessment and feedback of RELATE. We chose this combined program as couples can access and complete the combined RELATE with Couple CARE system at home, making it easy to disseminate. Based on the assumption that at least some couples would benefit from skill training, we predicted that relative to RELATE alone, RELATE with Couple CARE would reduce negative couple communication (Hypothesis 1) and assist couples to sustain relationship satisfaction (Hypothesis 2).

\section{Method}

\section{Participants}

Participants were 59 newlywed couples recruited for a study evaluating relationship enhancement programs that can be completed at home. Inclusion criteria for the study were that couples were currently cohabiting, both partners stated a willingness to participate, and neither partner was currently receiving psychotherapy for either an individual or couple relationship problem. The Register of Marriages mailed a package in July 2005, to all 224 couples married in the first week of June and in March 2006, to all 237 couples married in during the second week of February 2006, within the state of Queensland, Australia. The package included a 
letter from the Registrar stating that the personal details of the couples had not been released to the University, and participation by couples was voluntary. An enclosed brochure described the study and included a reply slip and prepaid envelope for couples to provide their contact information, or the couple could respond by e-mail to provide their contact details. ${ }^{1}$ Sixty seven couples responded to the invitation ( $14.7 \%$ of the invitations sent).

The mean age of participants was 36.3 years $(S D=10.7)$ for men and 34.2 years $(S D=10.2)$ for women. Mean annual income for men was $\mathrm{AUD}^{2} \$ 62,973(S D=32,323)$ and AUD $\$ 44,035(S D=26,108)$ for women. Twenty men $(34 \%)$ and 22 women (37\%) had been married previously, and 17 men $(29 \%)$ and 18 women $(31 \%)$ had children from a previous relationship. Twenty-seven men $(46 \%)$ and 30 women $(51 \%)$ had completed some university study. While all couples were newlyweds, 47 couples $(80 \%)$ had cohabited before marriage, and the mean duration of premarital cohabitation was 35 months $(S D=23.2)$. The sample can be characterized as typical of Australian marrying couples in age, proportion of remarriages, and frequency of premarital cohabitation, but participants were better paid and more highly educated than is typical of all Australian marrying couples. The sample was predominantly (94\%) Caucasian, which is similar to the ethnic composition of the population of Queensland.

\section{Measures}

The dependent measures in this study were observed couple communication and self-reported relationship satisfaction. Partners completed RELATE, (accessible at www .relate_institute.org), via the Internet as part of the pre-CRE assessment. RELATE-L, which is RELATE minus the demographic and family-of-origin questions that are not likely to change after CRE, was completed by all couples postCRE, which was 8 to 10 weeks after the pretest. RELATE-L also was completed at 12-month follow-up after the postCRE assessment. Relationship satisfaction was assessed from the RELATE satisfaction scale, which is a 7-item scale in which satisfaction is rated on a 5-point Likert scale from $1=$ "very dissatisfied" to $5=$ "very satisfied" with seven areas of the relationship such as intimacy, communication, and how conflict is managed. The scale had high reliability in the current sample $(\alpha=.85)$ and has established high test-retest reliability and sensitivity to change from CRE (Busby et al., 2007).

We also assessed communication before and after CRE. On each occasion couples were sent written instructions on having a problem discussion and a small audio-recorder. A research assistant rang the couple, explained the task and asked them to turn on the recorder and begin a 10-min discussion of a topic about which they disagreed. Twelve minutes later the assistant rang the couple back, thanked them for completing the task, and asked them to return the recorder in a prepaid reply envelope. The audio-recordings were coded using the RapidKPI (Halford et al., 2001). Each 30-s time interval was coded for the occurrence of each of three classes of negative communication: (a) conflict (criticize, negative solution); (b) invalidate (disagree, justify); and (c) negative nonverbal affect in each interval. Definitions of each code are available in Halford et al. (2001). The derived score was the percentage of intervals in which the particular behavior occurred. The scores discriminate between distressed and nondistressed couples, and are sensitive to changes in communication occurring from CRE (Halford et al., 2001). Two research assistants who were blind to the condition to which couples were assigned coded the videotapes. They received approximately 30 hours of training and then independently coded a random sample of one-third of all tapes. Observed intercoder agreement was high, with ICC $=.94$ for conflict, .93 for invalidate, and .97 for negative affect.

\section{RELATE With Couple CARE Program}

After the pre-CRE assessment couples were randomly assigned to receive either RELATE assessment and feedback (RELATE) or RELATE assessment and feedback plus the Couple CARE program (RELATE + CC). Couples in both conditions read through the computer-generated RELATE report that summarizes couple relationship strengths and challenges, and had a conjoint telephone-based session with a relationship educator to discuss the report and develop goals for relationship enhancement. RELATE is a 271-item online comprehensive assessment of a couple's relationship. RELATE is completed by both partners (Busby et al., 2001), and provides self-and partner-reports of current relationship strengths and challenges. The RELATE report provides information across 10 domains: relationship satisfaction, stability, relationship self-regulation, kindness and caring, effective communication, flexibility, conflict, conflict style, sexual intimacy, and problem areas. In each domain a graph is presented showing whether, relative to normative data developed on the RELATE measure, each partner's ratings classify this relationship domain as a strength, as neutral (described in the report as "OK"), or as a challenge domain for the relationship.

All couples were sent a 13 page RELATE report as a PDF e-mail attachment. The report describes the meaning of each scale, provides a graph showing each partner's scores, and defines these scores as a relationship strength, as neutral or as a challenge. The final page of the report shows the scale scores on a summary graph providing an overall profile of a couple's relationship strengths and challenges. The procedure used was similar to that in prior use of RELATE (e.g., Larson et al., 2007), and was developed with the authors of RELATE. It was suggested that each partner read through the report and then discuss it together. A relationship educator then rang the couple and spoke to them in a semi-structured conjoint interview about the report. Interviews were of 45 to $60 \mathrm{~min}$ duration. Partners were each asked about their overall reactions to

\footnotetext{
${ }^{1}$ Thirty-eight envelopes were returned marked "unknown at this address." Given that couples often change address around the time of marriage, it is likely that other couples did not receive the invitation to participate. Hence, the $15 \%$ response rate is likely an underestimate of the true response rate of couples that received the invitation.

${ }^{2}$ At the time of the study AUD $\$ 1.00 \approx$ US $\$ 0.80$.
} 
the report, what they identified as relationship strengths and challenges, and whether they agreed with the overall relationship profile presented in the report. The couple was then asked to define relationship enhancement goals, which could be either maintenance of existing strengths or changes to address relationship challenges.

We added one component to the procedure used in previous RELATE feedback evaluations. Each partner was asked to identify two specific behavior changes they wished to implement to enhance their relationship. Example goals included "to arrange a date together every two weeks" and "to ask more questions and not to interrupt when discussing difficult issues." This addition was intended to enhance the chance of specific actions being taken, and was based on similar specific goal setting that has been used to enhance change in health-related behaviors (e.g., Kypros \& McNally, 2005).

The details of Couple CARE and its delivery are described in Halford et al. (2004), and mental health professionals can access the program at www.couplecare.info. In brief, it is a 6-unit program in which couples complete each unit in about a week. The six units of Couple CARE cover the topics: relationship self-change, communication, intimacy and caring, managing differences, sexuality, and managing life changes. Completing each unit consists of the four steps described in the introduction. In the RELATE + CC program the telephone call at the end of the RELATE assessment explored the association between the couple's identified goals and the content of Couple CARE. For example, the educator pointed out to couples who reported difficulties with managing stress that Unit 6 of Couple CARE addresses this issue. Similarly, the educator pointed out to couples who reported problems with conflict that this issue was covered in Unit 4. While couples completed all 6 units from Couple CARE, the time and emphasis placed on each unit was tailored to address the specific needs of the couple.

\section{Relationship Educators}

Relationship education was provided by 2 male and 7 female educators. All educators had degrees in human services and were either experienced (5+ years) educators that had worked with Relationship Australia (Queensland) $(n=6)$, or were postgraduate clinical psychology students at Griffith University $(n=3)$. All educators completed a full day workshop on using the RELATE assessment and conducting the feedback interview, and a second full day on use of the Couple CARE program. These workshops included didactic instruction, demonstration and role play practice of skills in program delivery. Fortnightly group supervision sessions were conducted by the first three authors to provide additional training in RELATE and Couple CARE, and this was supplemented by individual case reviews conducted with educators by two of the authors and developers of the Couple CARE program, Elizabeth Moore and Charles Farrugia.

\section{Procedure}

When couples returned the reply paid envelope, or sent an e-mail, providing their contact details a research assistant contacted them. An initial screening interview was conducted with each partner to ensure couples understood what was involved in study participation and that they met the study inclusion criteria. Then couples were sent an informed consent form, and when that was returned they were sent information on how to access the RELATE Web site, and a small audio-recorder. Couples were telephoned, instructed on the communication task, and completed the task. The couple returned the audio-recorder in the prepaid reply envelope. Once the recorder was received, and the RELATE assessment completed, couples were telephoned and advised of the condition to which they had been assigned. Couples in both conditions then completed the RELATE assessment feedback call. The couples in the RELATE + CC condition then were sent the Couple CARE materials and had a regular (approximately weekly) telephone call with the educator that reviewed each of the 6 units after couples had completed the units.

Approximately 8 weeks after completion of the initial RELATE assessment couples were again mailed an audiorecorder and asked to complete a second communication task using the same procedure as in the pre-CRE communication assessment. Couples then completed RELATE-L assessment online. Twelve months later couples were contacted and asked to complete the RELATE-L online. Couples were prompted up to three times by telephone if they failed to complete any of the assessment tasks. Ethical approval for conduct of the study was given by the Human Research Ethics Committee of Griffith University.

\section{Results}

Figure 1 summarizes the flow of participants through the trial, and Table 1 presents the number of participants providing data, and means and standard deviations, on all measures at each time point. Of the 59 couples that began RELATE in two instances one partner never completed the RELATE assessment, leaving 57 couples who were randomly allocated to either RELATE + RELATE with Couple CARE. Of the 57 couples who completed the RELATE pre-assessment one couple's communication recoding was inaudible. Three couples (one in RELATE, 2 in RELATE + $\mathrm{CC}$ ) withdrew after completing the pre-CRE assessment but before beginning the assigned program. Three couples began but did not complete RELATE $+\mathrm{CC}$, and each of these three couples completed just the first unit. Six couples completed all or almost all of Couple CARE (at least 5 of the 6 units) but did not complete the post-CRE assessment. All couples that began RELATE completed the single telephone call and the post-CRE self-report assessment. Of the 44 couples that completed the self-report post-CRE assessment, two recorded communication tasks were inaudible and two couples declined to complete the post-CRE communication task, giving 40 couples that provided the communication postassessment.

\section{Data Analysis}

MLwiN (Rasbash, Browne, Healey, Cameron, \& Charlton, 2005) was used to conduct a two-level multilevel model 


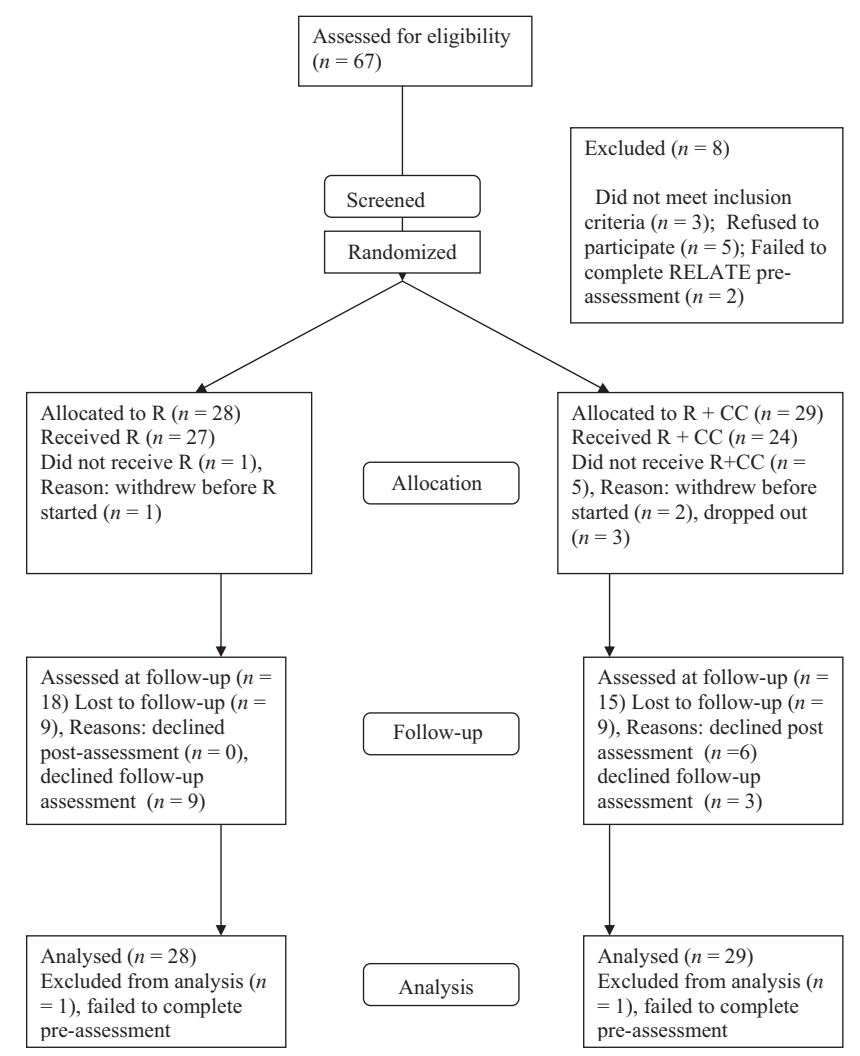

Figure 1. Participant flow through the study. $\mathrm{R}=$ RELATE, $\mathrm{R}+$ $\mathrm{CC}=$ Relate Plus Couple CARE. Number analyzed is equal to number of available assessments at preintervention as multilevel model (MLM) uses all available data and includes participants in the analysis with only some data.

(MLM) of intervention effects on each of the outcome measures. For each of the three indices of negative communication gender-specific repeated measures across the two occasions of measurement (pre- and post-CRE) formed Level 1, and couples formed Level 2, following Atkins (2005). The MLM was centered at pre-CRE, and occasion (pre-CRE $=0$, post-CRE $=1$ ) was entered as a covariate in the model giving an index of change between measurement occasions. Condition was then entered as a covariate $(\mathrm{RELATE}=0$, RELATE $+\mathrm{CC}=1)$ to test for genderspecific effects of condition on the intercept and change of negative couple communication. For relationship satisfaction gender-specific repeated measures across three occasions of measurement (pre- and post-CRE and 12 month follow-up) formed Level 1, and couples formed Level 2, following Atkins (2005). The MLM was centered at preintervention, and time in years (pre-CRE $=0$, post-CRE $=$ 0.2 , follow-up $=1.2$ ) was entered as a covariate in the model, which provides an estimate of the rate of linear change from pre-CRE to follow-up based on the three measurement occasions. As our couples were highly satisfied at pre-CRE, we did not expect a large change from preto post-CRE, but did expect that the slope of change in satisfaction through to 12-month follow up would differ between conditions. The MLM models use all available data to estimate parameters in the model, tests for genderspecific effects, and allows for the interdependence of partners' behavior (Atkins, 2005). The broad analytic plan used followed the recommendations of Singer and Willett (2003).

\section{Effects of Education on Couple Outcomes}

As is conventional with MLM, the models were developed sequentially. We began by conducting a variance component analysis. For each of the three indices of couple communication there was significant variance at both the couple and time levels, with the ICC of couple level variance being ICC $=.46$ for negative affect, $\mathrm{ICC}=.58$ for invalidation, and ICC $=.23$ for conflict. Table 2 presents the coefficients of the multi-level modeling of intervention effects. On each measure of couple communication there was no difference between conditions on the intercepts (i.e., pre-CRE means) for either gender. Relative to RELATE, in RELATE + CC male but not female negative affect declined, invalidation declined in women and showed a trend to decline in men, and conflict declined in women but not men. Thus, across the three measures of negative communication there was more decline in negative communication from pre- to post- CRE in RELATE + CC than in RELATE for at least one gender. Effect sizes were calculated by using the MLM coefficient to estimate mean communication scores at post-CRE for each gender in each condition, and dividing the difference between conditions' estimated means by the pre-CRE pooled standard deviation for the two conditions. The effect sizes of these changes ranged

Table 1

Sample Size, Means, and SDs (in Parentheses) on Outcome Measures at Each Assessment

\begin{tabular}{|c|c|c|c|c|c|c|}
\hline \multirow[b]{2}{*}{ Measure } & \multicolumn{3}{|c|}{ Woman } & \multicolumn{3}{|c|}{ Man } \\
\hline & Pre & Post & Follow-up & Pre & Post & Follow-up \\
\hline \multicolumn{7}{|c|}{ Observed communication } \\
\hline Sample size & 56 & 40 & - & 56 & 40 & - \\
\hline Negative speak & $12.5(16.6)$ & $13.0(18.8)$ & - & $19.2(23.6)$ & $20.4(22.1)$ & - \\
\hline Invalidate & $38.3(28.9)$ & $29.5(25.2)$ & - & $33.5(27.3)$ & $31.0(30.8)$ & - \\
\hline Negative affect & $28.0(29.8)$ & $32.6(30.3)$ & - & $35.2(31.1)$ & $38.8(34.2)$ & - \\
\hline \multicolumn{7}{|c|}{ Self-report measures } \\
\hline Sample size & 57 & 44 & 33 & 57 & 44 & 33 \\
\hline Satisfaction & $4.04(0.68)$ & $4.14(0.68)$ & $4.25(0.60)$ & $4.10(0.62)$ & $4.21(0.60)$ & $4.22(0.63)$ \\
\hline
\end{tabular}


Table 2

Multilevel Model of Couple Communication Before and After RELATE or RELATE With Couple Care

\begin{tabular}{|c|c|c|c|c|c|c|c|c|c|c|}
\hline \multirow[b]{2}{*}{ Behavior } & \multirow[b]{2}{*}{ Gender } & \multicolumn{4}{|c|}{ Intercept } & \multicolumn{5}{|c|}{ Slope } \\
\hline & & RELATE & RELATE + CC & $S E$ & $Z$ & RELATE & RELATE + CC & $S E$ & $Z$ & $d$ \\
\hline \multirow[t]{2}{*}{ Negative affect ${ }^{\mathrm{a}}$} & $\mathrm{M}$ & 27.2 & 28.6 & 7.7 & 0.19 & 13.3 & -6.7 & 10.6 & $1.88^{*}$ & 0.79 \\
\hline & F & 34.7 & 35.9 & 8.7 & 0.14 & 8.0 & 1.0 & 10.5 & 0.67 & - \\
\hline \multirow[t]{2}{*}{ Negative listening $^{\mathrm{a}}$} & M & 35.1 & 41.7 & 7.2 & 0.91 & -2.2 & -16.2 & 8.6 & $1.53^{\dagger}$ & 0.27 \\
\hline & $\mathrm{F}$ & 31.7 & 35.3 & 7.6 & 0.47 & 4.7 & -17.2 & 8.3 & $2.07^{*}$ & 0.62 \\
\hline \multirow[t]{2}{*}{ Negative speaking ${ }^{a}$} & M & 12.3 & 12.7 & 4.6 & 0.09 & 2.1 & -1.8 & 6.3 & 0.61 & - \\
\hline & $\mathrm{F}$ & 17.3 & 21.3 & 6.0 & 0.65 & 7.6 & -7.6 & 8.2 & $1.86^{*}$ & 0.38 \\
\hline \multirow[t]{2}{*}{ Relationship satisfaction $^{\text {b }}$} & $\mathrm{M}$ & 28.4 & 28.5 & 1.19 & 0.05 & 0.35 & 1.47 & 0.91 & 1.26 & - \\
\hline & $\mathrm{F}$ & 29.1 & 28.8 & 1.05 & 0.27 & -0.70 & 1.61 & 1.05 & $2.24^{*}$ & 0.42 \\
\hline
\end{tabular}

Note. RELATE + CC = RELATE with Couple CARE; $S E=$ standard error of the difference between the conditions.

${ }^{\mathrm{a}}$ Slope is the scale points change between pre- and postassessments. ${ }^{\mathrm{b}}$ Slope is expressed as scale point change per year.

${ }^{*} p<.05 . \quad{ }^{\dagger} p=.06$ (tests are one-tailed because the direction of difference between the conditions was specified in the hypothesis); $d=$ effect size of significant differences between conditions.

from a trend for a small effect on male invalidation, to moderate to large effects on female invalidation and male negative affect.

The variance component analysis of couple relationship satisfaction assessed on RELATE showed that there was significant variability at both the couple and time levels, ICC at the couple level $=0.61$. As shown in Table 2 there were no reliable differences in the intercept of male or female relationship satisfaction across conditions, showing the conditions were similar in relationship satisfaction before CRE. The slope of satisfaction across the next year was close to zero for men, reflecting little change and no difference between conditions. In contrast, women in the RELATE conditions showed a small decrease, while women in RELATE + CC showed an increase in satisfaction that was reliably different to the decrease seen in the RELATE women. Effect size was calculated by using the MLM coefficient to estimate mean relationship satisfaction at 12 month follow-up for women in each condition, and dividing the difference between conditions' estimated means by the pre-CRE pooled standard deviation. There was a moderate effect size of higher female relationship satisfaction after RELATE $+\mathrm{CC}$ relative to RELATE at follow-up.

Given the attrition from the study, we wanted to check that observed intervention effects were not an artefact of attrition. One-way two-level analyses of variance (ANOVAs) of missing data (none versus missing any data at either postintervention or follow-up) showed there were no differences on preintervention male or female relationship satisfaction, age of male and female partners, duration of cohabitation, or household income of couples. One-way two-level ANOVAs (complete data versus missing data at post-intervention) on the three measures of negative communication (invalidation, conflict, and negative affect) showed no differences in pre-intervention communication for drop outs versus completers for either men or women. Two-by-two $\chi^{2}$ analyses showed no difference on premarital cohabitation or remarriage status (first versus subsequent marriage) in couples that that provided all data versus couples that had at least one missing data point. Additional MLM analyses were run testing whether a dummy variable identifying couples that had any missing data (no missing data $=0$, missing data $=$ 1) predicted the outcomes (intercept or slope), or treatment effects. For each outcome missing data was added as a covariate to the unconditional growth models, then the test of condition effects. In none of these analyses on couple communication did the missing values variable predict the unconditional growth model intercepts or change, or moderate the intervention effects. Similarly, in the analysis on couple relationship satisfaction, the missing values variable did not predict the unconditional growth model intercept or slope, or moderate the intervention effect. Thus, missing data is unlikely to have produced an artefact of an intervention effect on the outcomes.

Table 2 shows the initial relationship satisfaction and slope of change. The clinical significance of observed intervention effects can be evaluated by examining means and change over time. RELATE women showed little change in satisfaction over the next 12 months after CRE, which was a mean of 28.412 months after CRE, while women in RELATE + CC increased satisfaction for the 12 months after CRE to a mean of 30.4. In a normative sample of $n=$ 492 cohabiting and recently married US couples, we found a mean female relationship satisfaction on RELATE of 25.7 $(S D=6.1)$. Thus, the current sample of women before RELATE + CC was on average about $0.5 S D$ more satisfied than other married couples, and 12 months after RELATE + CC women were on average $0.8 S D$ higher in satisfaction than the normative sample. Men in both conditions also were highly satisfied relative to our normative data $(M=$ 26.0, $S D=6.6$ ). Before CRE they were on average about $0.25 S D$ higher in satisfaction than normative sample of married couples, and 12 months after CRE had sustained or slightly increased the advantage in satisfaction relative to the normative sample. Thus, the satisfaction is being sustained at high levels and the intervention effect for women is further enhancing already high satisfaction.

\section{Discussion}

Hypothesis 1 was supported, RELATE $+\mathrm{CC}$ reduced couple negative communication more than RELATE. Hy- 
pothesis 2 was partially supported, RELATE + CC produced higher sustained female, but not male, relationship satisfaction than RELATE. This was the first study to evaluate the additive effects of curriculum-based skill training on assessment and feedback as forms of CRE. As predicted, the skill training Couple CARE program enhanced the reduction of negative couple communication and also enhanced maintenance of high female relationship satisfaction. In the absence of a no-intervention control, it is not possible to evaluate whether RELATE assessment and feedback had a beneficial effect for couples. However, most research finds satisfaction declines in recently married couples (e.g., Glenn, 1998), whereas the couples receiving RELATE in the current study showed no such decline. One previous study with a sample of couples in early-stage committed relationships found that RELATE enhanced couple relationship satisfaction (Larson et al., 2007), which suggests that Couple CARE might be incrementally enhancing the positive effects of RELATE on couple relationships, at least for the female partners.

It is not clear why women benefited from the addition of Couple CARE to RELATE but men did not. Halford et al. (2004) reported that women, but not men, showed an immediate increase in relationship satisfaction after Couple CARE relative to a wait list control, so the gender difference does seem reliable. However, in a face-to-face version of a program very similar to Couple CARE both men and women showed better maintenance of relationship satisfaction four years after CRE (Halford et al., 2001). It is possible that the flexible delivery format of Couple CARE works better for women than men. Alternatively, there is some evidence that changes in female relationship satisfaction might predict later male satisfaction (Petch \& Halford, 2008). Prevention of deteriorating satisfaction is only detectable when sufficient time has elapsed for comparison couples to show erosion of satisfaction. The lack of effect in men might be because of insufficient power to detect an intervention effect after only 12 months.

An important caveat on the additional benefits of COUPLE CARE for women beyond that of women completing RELATE is that 5 of 30 couples (14\%) dropped out from RELATE + CC and a further 6 couples declined post-CRE assessment in that condition. Supplementary analyses suggested that those that dropped out were not different at preintervention from those couples that provided data through to follow-up, nor did drop out status moderate the effects observed on the MLM analyses. The additional benefits of Couple CARE on couple communication or female relationship satisfaction seem unlikely to be an artefact of missing data, though replication of the current findings with a lower rate of missing data is needed to have confidence in this conclusion. The $14 \%$ attrition from RELATE + Couple CARE in the current study is similar to the $10 \%$ attrition from Couple CARE reported in an earlier study, though in the earlier study all completing couples provided post-CRE assessment data (Halford et al., 2004). The differences in willingness to provide post-CRE data between Halford et al. (2004) and the current study might be because of the level of contact with the educator. All couples in the Halford et al. (2004) attended face- to-face assessment interviews before and after CRE and selfreport measures were collected by the educator, whereas assessments were online in the current study and the only contact between educator and couples was by telephone. Perhaps the direct personal contact by Halford et al. enhanced willingness to provide data.

There is evidence that the extent and nature of personal contact with a professional moderates the effects of Internetbased interventions. Larson et al. (2007) found a face-to-face session with a relationship educator interpreting the RELATE report was more effective than just providing the report in enhancing couples' relationship satisfaction. In ongoing work Busby (personal communication, August 1, 2009) reports that telephone-based contact with an educator was associated with much lower attrition from Couple CARE than contact restricted to e-mail. Similarly, a meta-analysis of Internet-based treatments for anxiety and depression found therapist supported interventions produce substantially larger effect sizes than entirely self-directed interventions (Spek et al., 2007). Provision of the professional contact is an expensive element of intervention, and in future research it would be useful to test the cost-effectiveness of different amounts and type of professional contact.

In the current study we invited newlywed couples to participate in CRE, and approximately $15 \%$ of couples responded to the invitation. The recruitment method used was less costly than mass media advertisements, and had the advantage of allowing us to know the rate of agreement from the population of interest. However, this form of recruitment gave modest reach for CRE. We have no direct evidence on what influenced couple's decision whether to participate. It is known that about $30 \%$ of Australian marrying couples attends CRE premaritally (Halford et al., 2006). We did not specifically assess premarital $\mathrm{CRE}$ in the current sample, but it is likely that a similar proportion of couples we approached had participated in CRE in the months before their marriage, and they might not have wanted to participate in a second CRE program so soon after completing the first. Relying exclusively on recruitment into CRE soon after marriage might provide limited reach to couples. However, it is a previously unused window of opportunity to enhance couples' access to CRE, and given the ease of accessing contact details might constitute a useful supplement to existing offerings of CRE to couples in the lead up to marriage.

The current study had a predominantly white, well educated sample. People with low formal education, low income or ethnic minority status, are usually underrepresented in CRE for marrying couples (Halford et al., 2008). The generalizability of the benefits of CRE observed in the current and earlier studies to minority, less educated and economically disadvantaged partners is important but unknown, and testing this generalizability is currently the subject of several large scale trials (Halford et al., 2008).

In conclusion, the current study replicates earlier work that home-based couple relationship education can be effective. It also shows there are benefits to adding relationship skill training to couple assessment and feedback in terms of acquisition of relationship skills and maintenance of relationship satisfaction, particularly for women. However, the current study could not establish if the use of RELATE 
assessment and feedback enhanced the efficacy of Couple CARE. Future research should compare RELATE plus Couple CARE with Couple CARE alone, which could test the proposition that the RELATE assessment and feedback process is enhancing couple outcomes for couples completing Couple CARE directly. In addition, future research should examine the longer-term effects of the program, and which couples do and do not benefit.

\section{References}

Atkins, D. C. (2005). Using multilevel models to analyse couple and family treatment data: Basic and advanced issues. Journal of Family Psychology, 19, 98-110.

Bradbury, T. N., \& Karney, B. R. (2004). Understanding and altering the longitudinal course of intimate partnerships. Journal of Marriage and Family, 61, 451-463.

Busby, D. M., Holman, T. B., \& Taniguchi, N. (2001). RELATE: Relationship evaluation of the individual, family, cultural and couple contexts. Family Relations, 50, 308-317.

Busby, D. M., Ivey, D. C., Harris, S. M., \& Ates, C. (2007). Self-directed, therapist-directed, and assessment-based interventions for premarital couples. Family Relations, 56, 279-290.

Carroll, J. S., \& Doherty, W. J. (2003). Evaluating the effectiveness of premarital prevention programs: A meta-analytic review of outcome research. Family Relations, 52, 105-118.

Casey, L., \& Halford, W. K. (in press). Couples and the silicon chip: Applying technology to couple services. In K. Hahlweg, M. Grawe, \& D. Baucom (Eds.), Enhancing couples: The shape of couple therapy to come. Gottingen: Hogrefe.

Doherty, W. J., \& Anderson, J. R. (2004). Community marriage initiatives. Family Relations, 53, 425-432.

Doss, B. D., Rhoades, G., Stanley, S., \& Markman, H. J. (2009). Marital therapy, retreats, and books: The who, what, when, and why of relationship help-seeking. Journal of Marital and Family Therapy, 35, 18-29.

Duncan, S. F., \& Goddard, H. W. (2005). Family life education: Principles and practices for effective outreach. Thousand Oaks, CA: Sage.

Garb, H. N. (2007). Computer-administered interviews and rating scales. Psychological Assessment, 19, 4-13.

Glenn, N. D. (1998). The course of marital success and failure in five American 10-year marriage cohorts. Journal of Marriage and Family, 60, 569-576.

Guerney, B. G. (Ed.). (1987). Relationship enhancement manual. Bethesda, MD: Ideal.

Halford, W. K., Markman, H. J., Stanley, S., \& Kline, G. (2003). Best practice in relationship education. Journal of Marital and Family Therapy, 29, 385-406.

Halford, W. K., Markman, H. J., \& Stanley, S. M. (2008). Strengthening couple relationships with education: Social policy and public health perspectives. Journal of Family Psychology, 22, 497-505.

Halford, W. K., Moore, E. M., Wilson, K. L., Dyer, C., \& Farrugia, C. (2004). Benefits of a flexible delivery relationship education: An evaluation of the Couple CARE program. Family Relations, 53, 469-476.

Halford, W. K., O’Donnell, C., Lizzio, A. J., \& Wilson, K. L. (2006). Do couples at high risk of relationship problems attend pre-marriage education? Journal of Family Psychology, 92, 160-163.

Halford, W. K., Sanders, M. R., \& Behrens, B. C. (2001). Can skills training prevent relationship problems in at-risk couples? Four-year effects of a behavioral relationship education program. Journal of Family Psychology, 15, 750-768.

Halford, W. K., \& Wilson, K. L. (2009). Predictors of relationship satisfaction four years after completing flexible delivery couple relationship education. Journal of Couple and Family Therapy, 8, 123, 143-161.

Hawkins, A. J., Blanchard, V. L., Baldwin, S. A., \& Fawcett, E. B. (2008). Does marriage and relationship education work? A metaanalytic study. Journal of Consulting and Clinical Psychology, 76, 723-34.

Heyman, R. E. (2001). Observation of couple conflicts: Clinical assessment applications, stubborn truths, and shaky foundations. Psychological Assessment, 13, 5-35.

Holman, T. B. (2001). Premarital prediction of marital quality or breakup: Research, theory and practice. New York: Kluwer Academic/Plenum.

Knutson, L., \& Olson, D. H. (2003). Effectiveness of PREPARE program with premarital couples in community settings. Marriage and Family, 6, 529-546.

Kypri, K., \& McAnally, M. (2005). Randomized controlled trial of a web-based primary care intervention fro multiple health risk behaviors. Preventive Medicine, 41, 761-766.

Larson, J. H., \& Halford, W. K. (in press). One size does not fit all: Customizing couple relationship education for unique couple needs. Journal of Couple and Relationship Therapy.

Larson, J. H., Newell, K., Topham, G., \& Nichols, S. (2002). A review of three comprehensive premarital assessment questionnaires. Journal of Marital and Family Therapy, 28, 233-239.

Larson, J. H., Vatter, R. S., Galbraith, R. C., Holman, T. B., \& Stahmann, R. F. (2007). The Relationship Evaluation (RELATE) with therapistassisted interpretation: Short-term effects on premarital relationships. Journal of Marital and Family Therapy, 33, 364-374.

Lieberman, M. A., \& Goldstein, B. A. (2005). Self-help on-line: An outcome evaluation of breast cancer bulletin boards. Journal of Health Psychology, 10, 855-862.

Markman, H., Stanley, S., Blumberg, S., Jenkins, N., \& Whaley, C. (2004). Twelve hours to a great marriage. San Francisco, CA: Jossey-Bass.

Markman, H. J., Stanley, S. M., Jenkins, N. H., Petrella, J. N., \& Wadsworth, M. E. (2006). Preventive education: Distinctives and directions. Journal of Cognitive Psychotherapy, 20, 411-433.

Nicholson, J. M., Phillips, M., Whitton, S., Halford, W. K., \& Sanders, M. R. (2007). Promoting healthy stepfamilies: Couples' reasons for seeking help and perceived benefits from intervention. Family Matters, 77, 48-57.

Petch, J., \& Halford, W. K. (2008). Psychoeducation to enhance couples' transition to parenthood. Clinical Psychology Review, 28, 1125-1137.

Rasbash, J., Browne, W., Healey, M., Cameron, B., \& Charlton, C. (2005). MLwin Version 2.2. Bristol, England: University of Bristol Centre for Multi-level Modelling.

Singer, J. D., \& Willett, J. B. (2003). Applied longitudinal data analysis: Modeling change and event occurrence. New York: Oxford University Press.

Spek, V., Cuijpers, P., Nyklicek, I., Riper, H., Keyzer, J., \& Pop, V. (2007). Internet-based cognitive behaviour therapy for symptoms of anxiety and depression: A meta-analysis. Psychological Medicine, 37, 319-328.

Taylor, C., Jobson, K. O., Winzelberg, A., \& Abascal, L. (2002). The use of the internet to provide evidence-based integrated treatment programs for mental health. Psychiatric Annals, 32, 671-677.

Wilson, K. L., \& Halford, W. K. (2008). Processes of change in the flexible delivery of couple relationship education. Family Relations, 57, 625-635.

Received May 21, 2009

Revision received October 28, 2009 Accepted November 6, 2009 